\title{
Eco-friendly advertising:
}

A study of pictorial metaphors in environmental advertisements 
I. Abstract

\section{Anstract}

According to Cognitive Linguistics, metaphors are an essential cognitive tool to conceptualise certain domains of experience (Lakoff and Johnson 1980). Following this conception, it can be seen how advertising campaigns use metaphors with the aim of making advertisements more attractive.

In this line, this paper deals with the use of metaphors in environmental banners which aim at stopping climate change. The main aim of this study is to identify and analyse the underlying conceptual metaphors that help conceptualisers construe and reason about a collected set of environmental advertisements. This analysis is based on the conceptions related to conceptual metaphor (Evans and Green 2006; Kövecses 2002; Lakoff and Johnson 1980), as well as the ideas postulated by Charles Forceville (1996) on 'pictorial metaphors'.

Hence, six advertisements which use pictorial metaphors have been selected from a collection named Visual Metaphors in Advertising, available at the webpage www.pinterest.es. These advertisements have been analysed taking into account: the type of pictorial metaphor that they employ, the main conceptual metaphor embedded in each of them, the identification of its source and target domain and how part of the conceptual structure from the source domain is attributed to the target domain. By doing so, it is intended to show how eminent advertising corporations use this cognitive tool to make their creations more appealing to their potential viewers. The aforementioned analysis reveals that different types of pictorial metaphors are employed in contemporary advertising campaigns.

Keywords: Cognitive Linguistics, conceptual metaphor, pictorial metaphor, climate change, advertising.

\section{Introduction}

However unnoticed, the presence of metaphors in our daily lives, their importance in our society is worth remarking. Back in time, metaphor was thought to have a merely aesthetic function in poetry or speeches, as a rethoric tool. Nevertheless, thanks to the emersion of the Conceptual Metaphor Theory (Lakoff and Johnson 1980) (henceforward, CMT), this conception suffered a dramatic change. CMT proposed that metaphor is not just a linguistic phenomenon but a fundamental part of human thought. As a matter of fact, it is also important to claim that the term conceptual metaphor (henceforth, CM) was also coined at that moment. This groundbreaking work, accomplished by the two aforementioned 
authors, allowed us to see how metaphors are present in our surroundings not only in everyday talking or writing but also when thinking and reasoning (Lakoff and Johnson 1982).

Regarding the main focus of this paper, it aims at analysing the CMs employed in a collection of six advertisements published between 2004 and 2012. It is also worth mentioning that despite the fact that not all of them have been released in English-speaking countries, their potential audience was supposed to have a basic knowledge of this language. This is inferred from the use of English for informational purposes. The advertisements analysed deal with campaigns which aim at stopping climate change. Therefore, their importance in our present-day society derives from the influence of the corporations which released the aforementioned banners but also from their recent period of publication. The relevance of the topic dealt in the advertisements is of increasing importance in our society (Bosman 1987). Taking this into account, the CMs present in such advertisements will be studied in order to show how important this cognitive phenomenon is when conveying messages of enormous importance to wide audiences by means of advertising.

\subsection{Theoretical framework}

The main aim of this section is to introduce the Conceptual Metaphor Theory (CMT) and the four types of pictorial metaphors postulated by Forceville (1996) in order to fully understand the study presented in this paper.

\subsubsection{Conceptual Metaphor Theory (CMT)}

As it has been previously mentioned, metaphors used to be studied as stylistic devices employed for literary purposes or in speeches. However, Lakoff and Johnson (1980) introduced metaphors in the Cognitive Linguistics field in a revolutionary way. They claimed that metaphors played an important role beyond the linguistic level, being of extreme relevance when conceptualising ideas. Kövecses (2002) and Lakoff and Johnson (1980) share the idea that many everyday metaphors are conceptual in nature. In addition, it is also worth mentioning that these initial conceptual structures may, later on, result in linguistic metaphorical expressions.

These authors stated that metaphors contribute to the conceptualisation of a considerable variety of concepts, emotions and feelings. Furthe, metaphors help us to express and describe abstract concepts in an easier way (Lakoff and Johnson 1982). Metaphors imply the understanding of one idea in terms of another, e.g. time is money, love is a journey, argument is war, among others (Kövecses 2002). 
Lakoff and Johnson (1980) proposed to observe the notion CM as a way of understanding one idea, or conceptual domain, in terms of another. They claimed that a CM presented two main parts: the source and the target domain. The target domain represents the conceptual domain that we try to understand, whereas the source domain is the conceptual domain from which we draw metaphorical mappings in order to understand our target domain. In this light, Kövecses (2002) noted that target domains are commonly more abstract, whereas source domains are related to human body, animals, plants, food and forces, i.e. more concrete or embodied entities. "Target domains are abstract, diffuse and lack clear delineation; as a result, they 'cry out' for metaphorical conceptualisation" (Kövecses 2002, 20).

The mappings are the systematic set of correspondences that exist between constituent elements of the source and the target domain (Lakoff and Johnson 1980). Furthermore, it can be claimed that $\mathrm{CMs}$ are unidirectional. This unidirectionality implies that metaphors are conceptualised from a source domain to a target domain and that this relation cannot exist in the opposite way (Evans, and Green 2006).

\subsubsection{Categorisation of 'Pictorial Metaphors'}

Charles Forceville $(1996,2002,2007,2009)$ has developed and redefined a classification of notable importance when classifying what he coined pictorial metaphors. This type of metaphors, according to this author, are the ones in which the source and the target domains are linked exclusively by visual means. Following the classification of this author, we can differentiate four kinds of pictorial metaphors.

The first one is called Hybrid metaphor. In this type of pictorial metaphor, both the source and the target domains are partially depicted and joined together into one entity that is perceived as a single and unified object (Forceville 2009).

The second type of pictorial metaphor, according to this author, is called Pictorial simile. In this case, both the source and the target domains are visually depicted in their completeness as two separated figures, but in a way that exaggerates their similarity. In such cases, the resemblance can either be inherent in the two objects or created through the manner in which they are presented (Forceville 2002).

In third place, we can highlight Contextual metaphors. In this specific kind of pictorial metaphor, only the source or the target domain is depicted, in a context where normally something else would be expected to appear. The replacement of the anticipated entity encourages the audience to interpret one thing in terms of another (Forceville 1996). 
In fourth place, Integrated metaphor. In this type of pictorial metaphor, "a phenomenon that is experienced as a unified object or gestalt is represented in its entirety in such a manner that it resembles another object or gestalt even without contextual cues» (Forceville 2007, 18).

\subsection{Contextualisation}

In this section, a brief overview of the companies which released the advertisements analysed in this paper will be exposed. Then www.pinterest.es, the webpage in which the aforementioned adverts are gathered in a specific collection, will be introduced. Finally, the persuasive effect of metaphors employed for advertising purposes will be assessed.

Concerning the main firms which published the advertisements later discussed in this paper, we can mention Greenpeace, Bund and OroVerde. From the six banners comprised in this study, four of them have been released to the public by the well-known nongovernmental organisation Greenpeace. The rest of the advertisements have been published by the firms Bund and OroVerde, contributing each company one advertisement to this investigation.

However, it is important to state that despite the fact that the selected materials have been released by the companies mentioned above, they are gathered in a collection called Visual Metaphors in Advertisement. This compilation is available at the webpage www.pinterest.es, which does also have a mobile phone application. This site runs a software system designed to share information mainly by using images. This online tool was founded in the year 2010. It has reached two hundred million active users as of September 2017 (Omnicore Agency 2018).

Concerning the chronology in which the advertisements in this analysis have been published, it can be stated that they have been designed during the last fourteen years. In fact, the least recent ad was released in 2004 and the most recent in 2014. The contemporaneity of the discussed banners, which enables us to ensure their relevance in our nowadays society, is worth remarking.

Besides, as scholars have already stated, CMs are of extreme importance in current advertisement due to their great power of persuasion (Bosman 1987; Goatly 1997; Mio 1997; Pascual, and Silvestre-López 2015). Similarly, their studies do also suggest that this cognitive phenomenon makes advertising campaigns more attractive to the public, therefore they reach a wider number of visualisers. This conception is based on the fact that every conceptualiser makes use of CMs in an unconscious way. Hence, this paper aims at finding if the relevance of $\mathrm{CMs}$ in the world of advertisement, more 
specifically in the world of environmental advertising, is worth remarking.

\section{Aim}

The objective of this paper is to identify and analyse the CMs present in a collection of six advertisements which deal with climate change issues. The paper will show how prominent corporations make use of $\mathrm{CMs}$ in order to reach their audience in a successful way. More specifically, this paper will focus on how companies, whose main aim is to stop climate change and preserve our environment, make use of the aforementioned cognitive resource. By making use of CMs, they try to reach and convince wider audiences, since every conceptualiser uses this cognitive tool in an unconscious way.

It can also be observed how the analysis later developed in this paper is based on the CMs which are embedded in the selected advertisements. The analysed samples are examples of pictorial metaphors, therefore their monomodality is worth mentioning. Nonetheless, some of them show verbal cues as reinforcing devices. The study will take into account the conceptions pertaining to pictorial metaphor as formulated by Forceville, and Lakoff and Johnson, as well as Kövecses' conceptions related to CM.

\section{Method}

Regarding the methodology followed in the analysis, five steps will be taken. First of all, relevant studies related to the main topic of this paper were read, including a variety of works written by Lakoff and Johnson (1980, 1982), Forceville (1996, 2002, 2007, 2009), Kövecses (2002) and Evans and Green (2006). The categories of pictorial metaphors will be used taking into account their differences from multimodal metaphors, as well as a deep understanding of CMT.

Secondly, advertisements dealing with environmental issues were selected. They were retrieved from the webpage www.pinterest.es, more specifically from a collection available in this site called Visual Metaphors in Advertising. All the advertisements selected for the analysis were released to the market by eminent corporations in the last fourteen years. By doing so, the fact that the CMs employed in those ads reached a considerable number of viewers was secured. Their relevance in our nowadays society has further been assured taking into account that only contemporary material was selected. From the six analysed advertisements, four of them reach the metaphorical connection only through the use of images, and the other three count with a short text related to the metaphor exposed in them. However, all of them are monomodal 
metaphors, i.e. are accompanied by a text count with the verbal part as a reinforcement for the original metaphor showed by visual means. For that reason, if we omit the verbal cue, the connection between the source and the target domain would still be present.

Hence, once having accomplished the selection of advertisements for the analysis, the third step was to identify CMs. In order to accomplish this step, the information gathered during the initial readings was key.

In the fourth place, the CMs found were analysed. In order to accomplish this step, the conceptions around this concept followed by Lakoff and Johnson (1980) regarding conceptual metaphor theory and Forceville (1996) in relation to pictorial metaphors have been followed.

Finally, conclusions were drawn after reflecting upon the importance of CMs in our society. More specifically, when dealing with the advertisement field and drawing the audience's attention. Regarding the persuasive effects of metaphors in advertisements, the remarks reached in the studies developed by several authors have been followed (Bosman 1987; Goatly 1997; Mio 1997; Pascual, and Silvestre-López 2015).

\subsection{Materials}

The materials used this paper are six advertisements dealing with environmental topics. As it has been previously mentioned, they have been selected from the webpage www.pinterest.es. Regarding the firms which have been in charge of the production of the analysed advertisements, we can mention Greenpeace, Bund and Oroverde.

\section{Results and discussion}

This section is devoted to identifying and discussing the CMs which have been found in the aforementioned collection of environmental advertisements.

\subsection{THE EARTH IS A MELTING ICE-CREAM}

The hybrid pictorial metaphor which appears in the advertisement showed in the first advertisement is based on the CM THE EARTH IS A MELTING ICE-CREAM. Hence, its source domain is A MELTING ICE-CREAM and its target domain is THE EARTH.

In this advertisement released by Greenpeace in the year 2004, both the source and target domain are just linked by visual means. The source domain is identified by the representation of the icecream and the warmth which is jeopardising its correct status. This is clearly linked with the target domain, which in this specific case is 
the bad effect which is being caused to our planet by the warmth, caused by global warming.

In this way, the warmth causing the ice cream melt is metaphorically linked to global warming, which the organisation claims that is harming the earth. Following this line, Greenpeace claims that the poles, seen as the melting components of an icecream, are melting due to the increment of the temperatures which is affecting our planet. In the same way, this is connected with the idea of an ice cream melting due to the exposure to high temperatures, which is a much more familiar process to the visualiser of the advertisement.

\subsection{POLLUTING IS A VIDEOGAME}

The contextual pictorial metaphor which appears in the second advertisement analized is based on the CM POLLUTING IS A VIDEOGAME. Hence, its source domain is VIDEOGAME and its target domain is POLLUTING.

This second banner was published by the same nongovernmental organisation which released the previous banner, i.e. Greenpeace (2007). In this example, both the source and target domains are again represented only visually. Starting with the source domain, it can be seen how it is represented by the polluting nuclear power station depicted as a gaming killing weapon. In this way, a metaphorical connection between the killing potential of this nuclear plant and a weapon itself is established.

Moreover, the smoke emitted by this initial element can be interpreted as the bullets which may kill the potential victims in the arcade game. These potential victims are depicted as bears, which are linked to the target domain representing the whole environment endangered by the pollution.

Furthermore, this connection can also be seen in the relation between the pollution generated by the factories and the bullets appearing in the virtual pastime. These two elements are considered as having the same effect, i.e. killing or destroying. In addition, the main killing element, the nuclear power station, is showed as having the same features as a weapon in a computer game, i.e. the capacity of killing or destroying, due to the pollution that it emits.

Finally, this advertisement claims that polluters do not think that the way we pollute is going to affect our tangible world. So, the banner tries to illustrate that humanity is polluting as if we were in a videogame that can be stopped, i.e. without worrying about its repercussions, as if we were in a virtual world. 


\subsection{CLIMATE CHANGE IS A COUNTDOWN}

This third advertisement was published in 2011 by the German advertisement agency Bund. As it happened in the previous examples, both the source and target domain are represented only by visual means. The source domain is depicted by the clock and its advancing hands, which are illustrating the previously mentioned COUNTDOWN. Its moving sticks are squeezing the portrayed seal. So, taking this into account, we can identify the clock and its hands as the aforementioned threatening countdown for the environment.

Regarding the illustrated struggling mammal, we can identify it as a representation of the target domain. In this line, it can be observed how the way in which it is suffering the effects of the aforementioned countdown is representing the whole environment in danger. It can also be understood that the animal is suffering the pain caused by the countdown as a result of all the pollution which has been emitted and is currently harming our environment. In this way, the publishers are trying to portray how much time we have consumed as polluters and how little time we have left to stop this environmental phenomenon.

The visualisers exposed to this ad are forced to choose between two options. On the one hand, according to the advertisers, we can let the clock hands, moved by the pollution, advance. On the other hand, following the same campaign, we can stop them by reducing the levels of pollution and take a better care of the whole environment.

\subsection{DESTROYING THE EARTH IS WASTING PAPER}

The contextual pictorial metaphor which appears in the fourth advertisement is based on the CM DESTROYING THE EARTH IS WASTING PAPER. Thus, its source domain is WASTING PAPER and its target domain is DESTROYING THE EARTH.

This advertisement was published by the non-governmental organisation Greenpeace in 2007. In this case, both the source and target domain are again represented visually and verbally. In this light, it can be stated that the source domain is represented by the paper placed inside the dispenser. The way in which this paper is positioned illustrates the direct relationship between this material and the whole environment.

Regarding the target domain, it is represented by the shape of South America on the dispenser filled with paper. The connection between saving paper and saving the earth can be made. In this light, this material is representing the trees from where it is obtained. So, according to this advertisement, the more paper we consume, the more trees are going to be cut down. Therefore, our environment is going to be in danger, since the importance of forests for the 
maintenance of our environment is key. For that reason, the printed sentence in the paper dispenser illustrates the explained connection between the source and the target domain by giving a clear order: 'Save paper, save the planet'.

As it has happened with the previous example, the text appearing in the image is merely reinforcing the idea transmitted by the pictorial metaphor. In this sense, it can be affirmed that without the verbal cue, the metaphor would still be present in this particular example.

\subsection{FORESTS ARE LUNGS}

In this advertisement released in the year 2008 by Greenpeace, both the source and target domain are represented only by employing visual means. The source domain is represented by the shape of two human lungs, one of them being consumed as a sign of a disease. In the same line, the target domain is represented by the trees, gathered into a forest, which are forming the aforementioned form of two human lungs. It can be appreciated how they are being deforested; these trees are representing the whole environment in a jeopardised situation.

Hence, the deforestation which is affecting the forest is metaphorically linked to the possibility of it affecting not just trees but the whole nature, and especially human beings. It is suggested that the depicted deforestation can lead to breathing illnesses affecting human beings. This is based on the fact that pollution and deforestation reduce air quality, therefore it directly affects our lungs. Adisease affecting our lungs, and therefore, human beings can be caused.

\subsection{CAR POLLUTION IS DEFORESTATION}

In this banner released by OroVerde - The Tropical Forest Foundation in 2012, a silhouette representing South America is almost covered by the smoke emitted by a car. Both the source and target domains are represented visually. Firstly, the source domain is represented by the lack of green colour in the aforementioned shape, evoking the phenomenon of deforestation. In this light, the smoke is occupying the space where the green colour of the vegetation, missing as a consequence of the deforestation, is supposed to be.

Regarding the target domain, it is represented by the previously mentioned smoke. This fume, which is emitted by a car, is representing the air pollution in general caused by all types of combustion vehicles. So, taking this into account, this contamination is depicted as a cause of deforestation in the advertisement. The aforementioned advertising company is trying to convince us that 
the emissions emanated by contaminating vehicles are capable of destroying the whole nature. The authors of this ad suggest that car usage and all its related emissions must be controlled by us, human beings. By doing so, we would maintain our forests safe, since they are a key element when it comes to the preservation of our environment.

The text appearing at the bottom of the advertisement: 'every year we produce 3, 3 billion tons of $\mathrm{CO} 2$, that's why we need the rainforest more than ever' is giving more objective data. Nonetheless, however objective these data are, they are connected with the previous metaphorical analysis discussed above. In this line, when it says 'every year we produce 3, 3 billion tons of CO2', it refers to the target domain: CAR POLLUTION. In addition, when it claims that 'we need the rainforest more than ever', it refers to the fact that we must preserve our rainforests by stopping deforestation. In this light, trees play a crucial role in counteracting the effects of such an amount of $\mathrm{CO} 2$.

However, as it has happened with the rest of the examples containing verbal cues, the linguistic aspect which reinforces the visual metaphor originally transmitted could be omitted and the metaphor present in the advertisement would still remain meaningful. Hence, the main function of the written part in this example is to make the transmitted message more powerful.

\section{Conclusion}

The main objective of this paper was to identify and analyse the CMs appearing in the previously analysed advertisements in order to show how outstanding corporations make use of this cognitive resource with the purpose of reaching their audience successfully. This paper has also tried to show that these companies transmit their intended messages by making use of CMs since every conceptualiser uses this cognitive tool in a non-conscious way. Furthermore, this 'final undergraduate dissertation' had also as a goal to show the effect of globalisation in the analysed advertising campaigns and the way in which $\mathrm{CMs}$ are employed in them.

Regarding the initial expectations, they have been successfully reached after following the necessary steps. The selected advertisements show how CMs play such an important role in the advertising domain. In addition, the present study further suggests that metaphors make advertisements more appealing to the audience exposed to them since both the designers of the ads and the population exposed to them make use of $\mathrm{CMs}$ even without noticing. Therefore, this cognitive phenomenon is of vital importance in their daily lives, as it is present in every conceptualiser reasoning processes. 
Regarding the limitations of this paper, it can be said that despite the fact that the results present an initial understanding of the importance of CMs in current advertising, the results obtained cannot be generalised. This main limitation is due to the limited set of advertisements used in the analysis previously provided. As a consequence, a wider analysis should be accomplished by expanding the number of advertisements for analysis. By doing so, more reliable findings could be reached on this matter.

\section{References}

Bosman, Jan. 1987. "Persuasive effects of political metaphors.» Metaphor and Symbolic Activity 2 (2): 97-113.

El Refaie, Elisabeth. 2013. "Cross-modal resonances in creative multimodal metaphors: Breaking out of conceptual prisons.» Review of Cognitive Linguistics 11 (2): 236-249.

Evans, Vyvyan, and Melanie Green. 2006. Cognitive linguistics: An introduction. Edinburgh University Press.

Forceville, Charles. 1996. Pictorial Metaphor in Advertising. London and New York: Routledge.

Forceville, Charles. 2002. "Multimodal metaphor in ten Dutch TV commercials.» The Public Journal of Semiotics, 1 (1): 15-34.

Forceville, Charles. 2007. "The identification of target and source domain in pictorial metaphors." Journal of Pragmatics 34 (1): 114.

Forceville, Charles. 2009. «Non-verbal and multimodal metaphor in a cognitivist framework: Agendas for research.» In Multimodal metaphor, edited by Charles Forceville, and Eduardo UriosAparisi, 19-42. Berlin: Mouton de Gruyter.

Goatly, Andrew. 1997. The language of metaphors. London: Routledge.

Greenpeace USA. 2018. Retrieved from https://www.greenpeace.org/usa/.

Kövecses, Zoltán. 2002. Metaphor: A practical introduction. New York: Oxford University Press.

Lakoff, George, and Mark Johnson. 1980. Metaphors we live by. Chicago: Chicago University Press

Lakoff, George, and Mark Johnson. 1982. Metaphor and communication. Trier: L.A.U.T. 
Mio, Jeffery Scott. 1997. "Metaphor and Politics.» Metaphor and Symbol 12 (2): 113-133.

Pascual Hinojal, Clara, and Antonio José Silvestre-López. 2015. "Three-dimensional metaphorical objects in street advertising." RAEL: Revista Electrónica de Lingüística Aplicada 1 (14): 51-66.

Pinterest. 2018. Visual Metaphors in Advertising. Retrieved from https://www.pinterest.es/pin/165366617546576509/.

Pinterest. 2018. Visual Metaphors in Advertising. Retrieved from https://www.pinterest.es/pin/401946335478969085/.

Pinterest. 2018. Visual Metaphors in Advertising. Retrieved from https://www.pinterest.es/pin/490822059362385122/.

Pinterest. 2018. Visual Metaphors in Advertising. Retrieved from https://www.pinterest.es/pin/490822059362385130/.

Pinterest. 2018. Visual Metaphors in Advertising. Retrieved from https://www.pinterest.es/pin/490822059364715276/.

Omnicore Agency. 2018. Pinterest by the Numbers: Stats, Demographics \& Fun Facts. Retrieved from https://www.omnicoreagency.com/pinterest-statistics/. 